\title{
Menaquinone-4 in breast milk is derived from dietary phylloquinone
}

\author{
H. H. W. Thijssen ${ }^{1}$, M.-J. Drittij ${ }^{1}$, C. Vermeer ${ }^{2}$ and E. Schoffelen ${ }^{3}$ \\ Departments of ${ }^{1}$ Pharmacology and ${ }^{2}$ Biochemistry, University of Maastricht, Maastricht, The Netherlands \\ ${ }^{3}$ Centre of Midwifery, Maastricht, The Netherlands
}

(Received 20 March 2001 - Revised 5 October 2001 - Accepted 24 October 2001)

\begin{abstract}
The effect of maternal phylloquinone supplementation on vitamin $\mathrm{K}$ in breast milk was studied to establish: (1) if phylloquinone is the source of menaquinone-4 in breast milk; (2) the doseeffect relationship between intake and obtainable levels. Four groups of lactating mothers with a full-term healthy infant participated and took oral phylloquinone supplements of $0.0(n 8), 0 \cdot 8$ $(n 8), 2.0(n 8)$, and $4.0(n 7) \mathrm{mg} / \mathrm{d}$ for $12 \mathrm{~d}$, starting at day 4 post-partum. Milk samples were collected on days $4,8,16$, and 19 . Blood samples were collected on days 4 and 16 . Vitamin $\mathrm{K}$ and vitamin $\mathrm{E}$ concentrations, the latter for reason of comparison, were assayed. Phylloquinone and menaquinone-4 were present in all milk samples: 5.84 (SD 2.31) and 2.98 (SD 1.51) nmol/1 ( $n$ 31) respectively, in colostrum (day 4 sample). A strong correlation between the vitamers was found $(r$ 0.78, $P<0.001)$. Breast-milk phylloquinone levels were raised in a dose-dependent manner: 4-, 12-, and 30 -fold on day 16 for the $0 \cdot 8,2 \cdot 0$, and $4.0 \mathrm{mg}$ group respectively. In addition, menaquinone-4 levels were higher: $2 \cdot 5-(P<0 \cdot 05)$ and 7 -fold $(P<0 \cdot 001)$ in the $2 \cdot 0$ and $4.0 \mathrm{mg}$ groups respectively. Plasma of supplemented subjects contained 3-, 5-, and 10-fold higher phylloquinone levels on day 16. Detectable menaquinone- 4 was found in ten of thirtyone day 4 plasma samples. All day 16 plasma samples of the $4 \mathrm{mg}$ supplemented group contained the vitamin. There was no correlation between the K-vitamers in plasma. Vitamin E and phylloquinone appear to differ in their distribution in breast milk, milk:plasma concentration ratios were $\leq 1$ and 3-5 for vitamin $\mathrm{E}$ and phylloquinone respectively. The milk:plasma concentration ratio of menaquinone-4 was $>10$. In conclusion, dietary phylloquinone is a source of menaquinone-4 in breast milk. Phylloquinone supplementation to lactating mothers may be of benefit to the newborn infant, since both phylloquinone and menaquinone- 4 are raised by supplementation.
\end{abstract}

Breast milk: Menaquinone-4: Phylloquinone: Vitamin K: Prophylaxis

Vitamin $\mathrm{K}$ belongs to the fat-soluble vitamins. Its biological function is to act as a cofactor in essential post-translational $\gamma$-carboxylase reactions wherein substrate-molecule-specific glutamates are converted into $\gamma$ carboxyglutamates. Typical substrate molecules are the clotting factors II, VII, IX, and X. Other examples of substrate molecules are bone-gla-protein or osteocalcin and matrix-gla-protein, which play a role in bone maturation. Two molecular forms of vitamin $\mathrm{K}$ are known, phylloquinone (vitamin $\mathrm{K}_{1}$ ), which is present in plants as part of the electron transport in photosynthesis, and the menaquinones. Menaquinones, also known as vitamin $\mathrm{K}_{2}$, are synthesized by bacteria (Conly \& Stein, 1992). Instead of the phytyl side-chain present in phylloquinone, menaquinones have a polyisoprenoid side-chain. The menaquinones are designated by the number of isoprenoids, i.e. menaquinone- $n$ or MK- $n$. Major bacterial menaquinones synthesized by, for instance, the gut flora, are MK-7-11 (Ramotar et al. 1984; Kindberg et al. 1987).

Phylloquinone is the main dietary source of vitamin $\mathrm{K}$. Reports on daily phylloquinone intake are mainly from the USA. Estimated mean daily intakes are 60-160 $\mu \mathrm{g} / \mathrm{d}$ (Booth \& Suttie, 1998). The Food and Nutrition Board of the Institute of Medicine, the National Academies (Washington, DC, USA) has recently reported the adequate intake of vitamin $\mathrm{K}$ for adult men and women to be 120 and $90 \mu \mathrm{g} / \mathrm{d}$ respectively (Trumbo et al. 2001). Newborn infants have a higher need for vitamin K. The placenta forms a barrier, and this is the reason why infants are born with a relative vitamin K deficiency (Shearer, 1992; Greer, 1995). Furthermore, vitamin K levels in breast milk are low. Today's general strategy is to administer $1 \mathrm{mg}$

Abbreviation: MK-4, menaquinone-4.

* Corresponding author: Dr H.H.W. Thijssen, fax +31 4338841 49, email h.thijssen@farmaco.unimaas.nl 
phylloquinone at birth and to repeat phylloquinone prophylaxis in the wholly breast-fed child (Cornelissen et al. 1997; Sutor et al. 1999).

The contribution of menaquinones to vitamin $\mathrm{K}$ status is considered to be minor (Suttie, 1995). An exception may be MK-4. Several studies have reported that MK-4 is present in animal tissues. MK-4 is not a main bacterial product. Its presence in animal species, particularly domestic-bred species, may be the result of its formation from menadione. Menadione, a pro-vitamin $\mathrm{K}$ food additive, is transformed in vivo into MK-4 by the addition of the geranylgeranyl side-chain (Dialameh et al. 1971). Several studies reported on the in vivo synthesis of MK-4 from supplemented phylloquinone. Billeter \& Martius (1960), using radiolabelled phylloquinone, were the first to report on the exchange of the phytyl side-chain by the geranylgeranyl group in pigeons. More recently, by using HPLC techniques, the phylloquinone - MK-4 conversion was found to occur in chicks (Will et al. 1992) and rats (Thijssen \& Drittij-Reijnders, 1994). In addition, mice are able to synthesize MK-4 from phylloquinone (HHW Thijssen and M-J Drittij, unpublished results). The biological significance of this conversion is not known. Studies in rats suggest that MK-4 may be the preferred substrate for non-hepatic tissues (Thijssen et al. 1996). Human tissues were also found to accumulate MK-4 (Thijssen \& Drittij-Reijnders, 1996). Whether MK-4 in man originates from food products like eggs and chickenmeat that contain limited amounts of MK-4 (Ronden, 1998), or whether human tissue can also convert dietary phylloquinone into MK-4 is not known.

We addressed the question of the phylloquinone MK-4 conversion in human subjects by studying the concentrations of MK-4 in breast milk. Milk of various species, including that from human subjects, has been found to contain MK-4 (Hiraike et al. 1988; Indyk \& Woollard, 1997). Phylloquinone and MK-4 levels in plasma and milk were followed with time after supplementing lactating mothers different daily doses of phylloquinone. For reason of comparison we also measured vitamin $\mathrm{E}$ concentrations. The levels of vitamin $\mathrm{E}$ in human milk have been reported (Chappell et al. 1985; Boersma et al. 1991). Our present study shows that MK-4 in breast milk is associated with the phylloquinone status and that it is raised by maternal phylloquinone supplementation.

\section{Subjects and methods}

Mothers, at term of pregnancy, were recruited from a centre of midwifery. Inclusion criteria were: uncomplicated pregnancy with a healthy full-term ( $>37$ week) infant and breast-feeding. Exclusion criteria were: drug use and/or abuse; gastrointestinal dysfunction of the mother or the infant; low $(<50 \mathrm{~kg})$ or high $(>90 \mathrm{~kg})$ body weight of the mother. The study had the approval of the Medical Ethical Committee of the University of Maastricht. Informed consent was obtained from all the participants. The study was stratified to contain four groups of eight mothers to be supplemented with either $0.0,0.8,2 \cdot 0$, or $4.0 \mathrm{mg}$ phylloquinone/d. Participants were randomly assigned to a group in order of entrance into the study. The study was performed between September 1998 and August 1999.

Mothers gave birth at home. Standard procedures according to the Dutch Society for Pediatry were followed for vitamin $\mathrm{K}$ prophylaxis, i.e. $1 \mathrm{mg}$ phylloquinone orally at birth and $25 \mu \mathrm{g} / \mathrm{d}$ from post-partum day 8 for the wholly breast-fed infant. Phylloquinone supplementation (Konakion MM, $10 \mathrm{mg} / \mathrm{ml}$; Roche, Basel, Switzerland) was started at day 4 post-partum to continue until day 16 . Participants were instructed to take the vitamin daily in the afternoon. Administration was by drops in a drink (tea or soft drink): two, five and ten drops for the $0.8,2 \cdot 0$ and $4.0 \mathrm{mg}$ dose respectively. No special dietary advice was given to the mothers. On day 4, between 08.00 and 11.00 hours, a venous blood sample was taken and 5-10 ml milk were collected by means of a manual pump device. Further milk samples were collected on days 8, 16, and 19 before 11.00 hours. Milk was taken from the breast that had not been used for the previous feed. The first $10 \mathrm{ml}$ of the collected milk were discarded and the second $5-10 \mathrm{ml}$ were taken as a sample. A second blood sample was taken on day 16 in the morning. Blood and milk sampling were done by a well-instructed medical female student who visited the mothers at home. Milk and blood samples were kept in the dark and transported as soon as possible (within $4 \mathrm{~h}$ ) to the laboratory. Plasma and milk were stored at $-70^{\circ} \mathrm{C}$ until analysis.

\section{Biochemical analysis}

Vitamin $K$ and vitamin $E$ ( $\alpha$ - and $\gamma$-tocopherol) in plasma. To $1 \mathrm{ml}$ plasma was added $2 \mathrm{ml}$ ethanol and $0.1 \mathrm{ml}$ 2-propanol containing $0 \cdot 500 \mathrm{ng} 2^{\prime}, 3^{\prime}$-dihydrophylloquinone and $25 \mu \mathrm{g} \alpha$-tocopherol nicotinate as the internal standards for vitamin $\mathrm{K}$ and vitamin $\mathrm{E}$ respectively. The mixture was shaken thoroughly for $5 \mathrm{~min}$, whereupon the vitamins were extracted in $3.5 \mathrm{ml} n$-hexane. A portion of the hexane fraction $(0.3 \mathrm{ml})$ was used for vitamin $\mathrm{E}$, and a further portion $(3 \mathrm{ml})$ for vitamin $\mathrm{K}$, analysis. The vitamin $\mathrm{K}$ fraction was cleaned by adsorption and desorption on silica (Thijssen et al. 1996). The final vitamin K-containing fraction was dissolved in $0.05 \mathrm{ml}$ 2-propanol. The residue of the vitamin $\mathrm{E}$ fraction was dissolved in $0.1 \mathrm{ml}$ 2-propanol.

Vitamin $K$ and vitamin $E$ in milk. Milk $(1.1 \mathrm{ml})$ was incubated with $0 \cdot 1 \mathrm{~g}$ lipase (type VII; Sigma Chemicals, $\mathrm{St}$ Louis, MO, USA) for $2 \mathrm{~h}$ at $37^{\circ} \mathrm{C}$. A portion $(0 \cdot 1 \mathrm{ml})$ was separated for glycerol (triacylglycerol) analysis. The remaining $1 \mathrm{ml}$ digested milk was mixed with $1 \mathrm{ml}$ sodium carbonate $(100 \mathrm{~g} / \mathrm{l}), 2 \mathrm{ml}$ ethanol and $0.1 \mathrm{ml}$ mixture of internal standards (see earlier). The mixture was shaken for 15 min. Extraction and work-up was done as for plasma samples.

The extracted $\mathrm{K}$ vitamins were quantified by fluorescence detection following HPLC separation (Thijssen et al. 1996) and post-column reduction with a Zn-column (Haroon et al. 1986). The E vitamins were quantified by HPLC and u.v. $(295 \mathrm{~nm})$ detection using a Nucleosil $\mathrm{C}_{18}$ column (Chrompack, Bergen op Zoom, The Netherlands) with methanol-acetonitrile-water (110:30:7, by vol.) as mobile phase. 
Mixtures of phylloquinone, MK-4 (range $0 \cdot 2-200 \mathrm{nmol} / \mathrm{l}$ ), $\alpha$ - and $\gamma$-tocopherol (range $0 \cdot 2-120 \mu \mathrm{mol} / \mathrm{l}$ ) were prepared in $4 \mathrm{~g}$ bovine serum albumin/l PBS to construct calibration curves. Extraction efficiency from bovine serum albumin in PBS was $>90 \%$ for all the vitamins. The CV for the intra-assay accuracy for vitamin $\mathrm{K}$ and vitamin $\mathrm{E}$ in plasma (two samples, four analyses each) were 7 and 6\% respectively. In milk, the $\mathrm{CV}$ were 8 and $6 \%$. With each thirty samples three calibration points were included with the assays.

Triacylglycerol concentrations in plasma and milk were assayed using a commercial kit (Sigma Chemicals).

\section{Statistics}

The results are presented as means values and standard deviations. Log-transformed data were used (except for the triacylglycerol levels in plasma) for statistical analysis. Applied statistic tests were ANOVA followed by TukeyKramer multiple comparison test. Fisher's Exact test was applied to compare the presence of detectable MK-4 in plasma. The software program Instat (GraphPad Software, San Diego, CA, USA) was used for the calculations.

\section{Results}

The planned breast-milk samples were obtained from thirty-one mothers. One mother (4 mg group) withdrew from the study. Three mothers, all belonging to the $0.8 \mathrm{mg}$ group, objected to giving the second blood sample (day 16). Furthermore, results suggested that at least two participants did not fully complete the supplementation schedule. The phylloquinone levels in the day 16 (postpartum day 16) samples of one subject in the $2 \mathrm{mg}$ group and one in the $0.8 \mathrm{mg}$ group were less than $20 \%$ of the levels found at day 8. For the former subject this was also reflected in the plasma phylloquinone levels on day 16, which were within normal range. The day 16 and 19 breast-milk results and the day 16 plasma results of these mothers were not included in the analysis. The day 16 plasma sample of one subject in the $4 \mathrm{mg}$ group was lost.

\section{Vitamin $K$ in breast milk}

The observed vitamin $\mathrm{K}$ concentrations in breast milk are summarized in Table 1. Both phylloquinone and MK-4 were found to be present in breast milk. The colostrum (day 4 samples, $n$ 31) levels of phylloquinone and MK-4 were 5.84 (SD 2.31) and 3.18 (SD 1.53) nmol/1 respectively. MK-4 concentrations correlated significantly with phylloquinone (Fig. 1; $r$ 0.78, $P<0.001$ ). There were no differences in baseline values between the groups. Phylloquinone concentrations on days 8,16 and 19 of the control group did not differ from levels on day 4. The MK-4 levels tended to decline, but the differences were not significant. Maternal phylloquinone supplementation significantly increased $(P<0.001)$ the vitamin $\mathrm{K}$ levels in breast milk. On day 16 the phylloquinone concentrations were 4.87 (SD 1.43), 24.51 (SD 10.14), 60.64 (SD 31.6) and $139.64(\mathrm{SD} 45.83) \mathrm{nmol} / \mathrm{l}$ in the control, the $0.8,2.0$ and $4.0 \mathrm{mg}$ groups respectively. MK-4 was also found to



Fig. 1. Relationship between phylloquinone $\left(K_{1}\right)$ and menaquinone-4 (MK-4) levels in breast milk at day 4 (colostrum) ( $r 0.78$, $P<0.0001$ ). $\diamond$, Control; $\square, 0.8 \mathrm{mg}$ group; $\Delta, 2 \mathrm{mg}$ group; $\bigcirc, 4 \mathrm{mg}$ group. For details of subjects and procedures, see p. 220.

increase after the phylloquinone supplementation. In particular, the MK-4 levels in the days 8 and 16 samples of the $4 \mathrm{mg}$ group was significantly higher $(P<0.05$ and $P<0.001$ respectively). The $2 \mathrm{mg}$ group had significantly higher levels at day 16 (Table $1 ; P<0 \cdot 05$ ). Again, a highly significant correlation between the concentrations of MK-4 and phylloquinone was found (Fig. 2; $r 0.90, P<0.001$ ). Four days after cessation of the phylloquinone supplementation, breast-milk concentrations (day 19 samples) were significantly lower, $70-80 \%$ for phylloquinone $(P<0.001), 50-60 \%$ for MK-4 (in the $4 \mathrm{mg}$ group, $P<0.05)$.

Higher menaquinones, i.e. MK-6 - MK-8, were found in some of the milk samples. If present the levels were low, and no association was found with phylloquinone supplementation. The epoxide of phylloquinone, but not

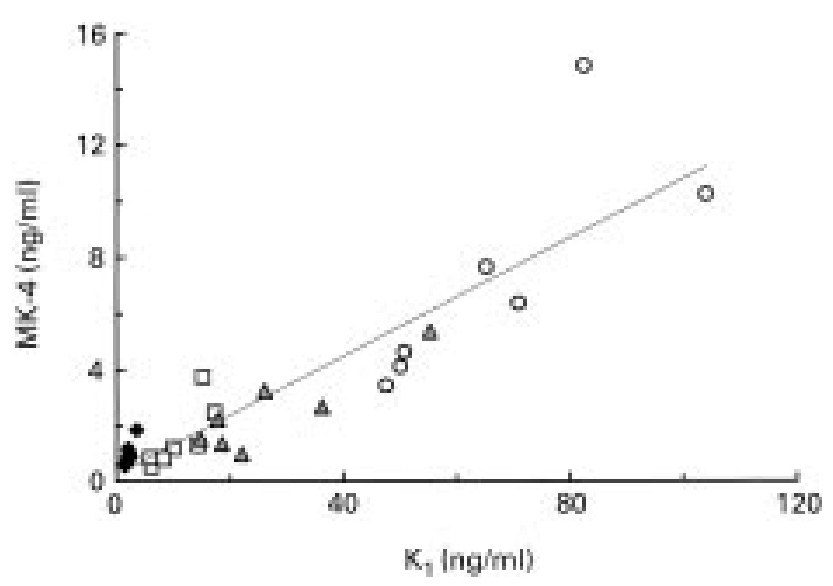

Fig. 2. Relationship between phylloquinone $\left(K_{1}\right)$ and menaquinone-4 (MK-4) levels in breast milk after maternal supplementation with phylloquinone for $16 \mathrm{~d}$. $(r 0.90, P<0.0001)$. Control group (n 8), $r 0.92, P=0.001 ; \square, 0.8 \mathrm{mg}$ group $(n 7), r 0.79, P<0.05 ; \Delta$, $2 \mathrm{mg}$ group $(n 7), r 0.89, P<0.01 ; 0,4 \mathrm{mg}$ group $(n 7), r 0.78$, $P<0.05$. For details of subjects and procedures, see p. 220 . 
Table 1. The effect of maternal phylloquinone $\left(\mathrm{K}_{1}\right)$ supplementation on menaquinone-4 (MK-4) and phylloquinone levels (nmol/l) in breast milk§ (Mean values, standard deviations and $95 \%$ confidence intervals)

\begin{tabular}{|c|c|c|c|c|c|c|c|c|c|c|c|c|c|c|c|c|}
\hline & \multicolumn{4}{|c|}{ Day 4} & \multicolumn{4}{|c|}{ Day 8} & \multicolumn{4}{|c|}{ Day 16} & \multicolumn{4}{|c|}{ Day 19} \\
\hline & \multicolumn{2}{|l|}{ MK-4 } & \multicolumn{2}{|l|}{$\mathrm{K}_{1}$} & \multicolumn{2}{|l|}{ MK-4 } & \multicolumn{2}{|l|}{$\mathrm{K}_{1}$} & \multicolumn{2}{|l|}{ MK-4 } & \multicolumn{2}{|l|}{$\mathrm{K}_{1}$} & \multicolumn{2}{|l|}{ MK-4 } & \multicolumn{2}{|l|}{$\mathrm{K}_{1}$} \\
\hline & Mean & SD & Mean & SD & Mean & SD & Mean & SD & Mean & SD & Mean & SD & Mean & SD & Mean & SD \\
\hline \multicolumn{17}{|l|}{ Control group } \\
\hline $\begin{array}{l}\text { Mean value } \\
95 \% \mathrm{Cl} \\
n\end{array}$ & $\begin{array}{l}2.97 \\
1.39,4.55 \\
8\end{array}$ & 1.89 & $\begin{array}{l}5 \cdot 51 \\
3 \cdot 44,7.58\end{array}$ & $2 \cdot 47$ & $\begin{array}{l}2.59 \\
0.77,4.41 \\
8\end{array}$ & $2 \cdot 18$ & $\begin{array}{l}4.37 \\
1.84,6.90\end{array}$ & 3.03 & $\begin{array}{l}2 \cdot 15 \\
1 \cdot 39,2 \cdot 91 \\
8\end{array}$ & 0.90 & $\begin{array}{l}4.87 \\
3 \cdot 67,6 \cdot 07\end{array}$ & 1.43 & $\begin{array}{l}1 \cdot 78 \\
1 \cdot 27,2 \cdot 30 \\
8\end{array}$ & 0.62 & $\begin{array}{l}4 \cdot 80 \\
2 \cdot 33,7 \cdot 28\end{array}$ & $2 \cdot 96$ \\
\hline $0.8 \mathrm{mg}$ group & & & & & & & & & & & & & & & & \\
\hline $\begin{array}{l}\text { Mean value } \\
95 \% \mathrm{Cl} \\
n\end{array}$ & $\begin{array}{l}3 \cdot 84 \\
2 \cdot 73,4.95 \\
8\end{array}$ & $1 \cdot 33$ & $\begin{array}{l}6 \cdot 84 \\
4.92,8.75\end{array}$ & $2 \cdot 29$ & $\begin{array}{l}2 \cdot 69 \\
1.03,4.35 \\
7\end{array}$ & $1 \cdot 80$ & $\begin{array}{l}23 \cdot 33^{\star \star} \\
9 \cdot 72,36 \cdot 95\end{array}$ & $14 \cdot 72$ & $\begin{array}{l}3 \cdot 48 \\
1 \cdot 09,5 \cdot 88 \\
7\end{array}$ & $2 \cdot 59$ & $\begin{array}{l}24 \cdot 51^{\star \star *} \\
15 \cdot 15,33 \cdot 91\end{array}$ & $10 \cdot 14$ & $\begin{array}{l}3 \cdot 23 \\
0 \cdot 64,6 \cdot 02 \\
7\end{array}$ & 2.56 & $\begin{array}{l}12.35 \\
0.77,23.92\end{array}$ & $12 \cdot 51$ \\
\hline \multicolumn{17}{|c|}{$2.0 \mathrm{mg}$ group } \\
\hline $\begin{array}{l}\text { Mean values } \\
95 \% \mathrm{Cl} \\
n \\
4.0 \mathrm{mg} \text { group }\end{array}$ & $\begin{array}{l}2 \cdot 55 \\
1 \cdot 71,3 \cdot 40 \\
8\end{array}$ & 1.00 & $\begin{array}{l}5 \cdot 15 \\
3 \cdot 08,7 \cdot 23\end{array}$ & $2 \cdot 48$ & $\begin{array}{l}3 \cdot 84 \\
2 \cdot 27,5 \cdot 41 \\
8\end{array}$ & $1 \cdot 88$ & $\begin{array}{l}41.34^{\star \star \star} \\
11.11,71.63\end{array}$ & $36 \cdot 18$ & $\begin{array}{l}5 \cdot 54^{\star} \\
2 \cdot 42,8 \cdot 67 \\
7\end{array}$ & $3 \cdot 38$ & $\begin{array}{l}60 \cdot 64^{\star \star *}+\dagger \\
31.41,89.87\end{array}$ & $31 \cdot 60$ & $\begin{array}{l}3 \cdot 01 \\
1 \cdot 77,4 \cdot 25 \\
7\end{array}$ & $1 \cdot 34$ & $\begin{array}{l}12 \cdot 07 \\
7 \cdot 78,16 \cdot 37\end{array}$ & $4 \cdot 64$ \\
\hline $\begin{array}{l}\text { Mean value } \\
95 \% \mathrm{Cl} \\
n\end{array}$ & $\begin{array}{l}3 \cdot 81 \\
2 \cdot 20,5 \cdot 42 \\
7\end{array}$ & $1 \cdot 74$ & $\begin{array}{l}6 \cdot 21 \\
4 \cdot 49,7 \cdot 93\end{array}$ & $1 \cdot 86$ & $\begin{array}{l}9 \cdot 86^{\star} \dagger \\
1 \cdot 24,18 \cdot 48 \\
7\end{array}$ & $9 \cdot 32$ & $\begin{array}{l}88 \cdot 72^{\star \star \star} \dagger \dagger \\
48 \cdot 67,128.77\end{array}$ & 43.40 &  & $9 \cdot 15$ & 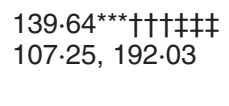 & $45 \cdot 83$ & $\begin{array}{l}8.98^{\star *} \dagger \ddagger \\
3 \cdot 52,14.42 \\
7\end{array}$ & $5 \cdot 18$ & $\begin{array}{l}44.88^{* *} \ddagger \\
3.08,86 \cdot 70\end{array}$ & $39 \cdot 83$ \\
\hline \multicolumn{17}{|c|}{ All groups for Days 4, 8, 16 and 19} \\
\hline $\begin{array}{l}\text { Mean value } \\
95 \% \mathrm{Cl} \\
n\end{array}$ & $\begin{array}{l}3 \cdot 18 \\
2 \cdot 62,3 \cdot 75 \\
31\end{array}$ & 1.53 & $\begin{array}{l}5.84 \\
4.99,6.69\end{array}$ & $2 \cdot 31$ & & & & & & & & & & & & \\
\hline
\end{tabular}

Mean values were significantly different from those of the control group: * $P<0.05,{ }^{* \star} P<0.01,{ }^{* \star \star} P<0.001$.

Mean values were significantly different from those of the $0.8 \mathrm{mg}$ group: $+P<0.05,+\uparrow P<0.01,+1+P<0.001$

Mean values were significantly different from those of the $2.0 \mathrm{mg}$ group: $\ddagger P<0.05, \ddagger \ddagger P<0.01, \ddagger \neq \ddagger P<0.001$

$\S$ For details of subjects and procedures, see p. 220. 
Table 2. The effect of maternal phylloquinone $\left(\mathrm{K}_{1}\right)$ supplementation on plasma menaquinone-4 (MK-4) and phylloquinone levels (mmol/l) in lactating mothers $\ddagger$

(Mean values, standard deviations and $95 \%$ confidence intervals)

\begin{tabular}{|c|c|c|c|c|c|c|c|c|}
\hline & \multicolumn{4}{|c|}{ Day 4} & \multicolumn{4}{|c|}{ Day 16} \\
\hline & \multicolumn{2}{|c|}{ MK-4§ } & \multicolumn{2}{|c|}{$\mathrm{K}_{1}$} & \multicolumn{2}{|c|}{ MK-4§ } & \multicolumn{2}{|c|}{$\mathrm{K}_{1}$} \\
\hline & Mean & SD & Mean & SD & Mean & SD & Mean & SD \\
\hline \multicolumn{9}{|l|}{ Control group } \\
\hline Mean value & 0.18 & 0.04 & 2.56 & 1.72 & 0.26 & 0.21 & $3 \cdot 15$ & 1.98 \\
\hline $95 \% \mathrm{Cl}$ & $0.08,0.28$ & & $1.11,4.00$ & & $0.00,0.61$ & & $1.50,4.81$ & \\
\hline$n$ & 3 & & 8 & & 4 & & 8 & \\
\hline \multicolumn{9}{|l|}{$0.8 \mathrm{mg}$ group } \\
\hline Mean value & 0.20 & 0.07 & $2 \cdot 04$ & 2.03 & 0.22 & 0.03 & $9 \cdot 37^{\star}$ & $6 \cdot 75$ \\
\hline $95 \% \mathrm{Cl}$ & $0.10,0.31$ & & $0.34,3.74$ & & $0.00,0.51$ & & $0 \cdot 00,20 \cdot 12$ & \\
\hline$n$ & 4 & & 8 & & 2 & & 4 & \\
\hline \multicolumn{9}{|l|}{$2.0 \mathrm{mg}$ group } \\
\hline Mean value & 0.37 & & $3 \cdot 10$ & $2 \cdot 21$ & 0.24 & 0.01 & $15 \cdot 28^{* \star *}$ & 8.08 \\
\hline $95 \% \mathrm{Cl}$ & & & $1.26,4.95$ & & $0.00,0.50$ & & $7 \cdot 81,22 \cdot 76$ & \\
\hline$n$ & 1 & & 8 & & 3 & & 7 & \\
\hline \multicolumn{9}{|l|}{$4.0 \mathrm{mg}$ group } \\
\hline Mean value & 0.18 & 0.09 & $2 \cdot 63$ & 1.76 & 0.42 & 0.23 & $31 \cdot 64^{\star \star \star} \dagger$ & $8 \cdot 16$ \\
\hline $95 \% \mathrm{Cl}$ & $0.00,1.04$ & & $1 \cdot 00,4.26$ & & $0.17,0.67$ & & $13 \cdot 07,40 \cdot 21$ & \\
\hline$n$ & 2 & & 7 & & $6 \|$ & & 6 & \\
\hline
\end{tabular}

Mean values were significantly different from those of the control group: ${ }^{\star} P<0.05,{ }^{* \star *} P<0.001$.

Mean value was significantly different from that of the $0.8 \mathrm{mg}$ group: $\dagger P<0.05$.

¥ For details of subjects and procedures, see p. 220.

$\S$ For MK-4, $n$ refers to the number of plasma samples containing measurable amounts.

$\| P=0.051$, Fisher's exact test for the presence of detectable MK-4 in plasma.

of MK-4 nor of the higher menaquinones, was also found to be present in some of the samples.

To see whether the vitamin $\mathrm{K}$ status depends also on the fat content, triacylglycerol levels were estimated. Triacylglycerol levels increased significantly with time: $28 \cdot 1$ (SD 8.6), 35.1 (SD 20.1), 40.2 (SD 15.3), and 47.2 (SD 15.7) $\mathrm{mmol} / \mathrm{l}$ for days $4,8,16$ and 19 respectively $(P<0 \cdot 01$, days 16 and $19 v$. day 4). No correlation between triacylglycerol and vitamin $\mathrm{K}$ concentrations was found.

\section{Vitamin $K$ in plasma}

Plasma vitamin $\mathrm{K}$ concentrations are summarized in Table 2. Day 4 plasma phylloquinone concentrations ranged from 0.5 to $7.2 \mathrm{nmol} / \mathrm{l}$ (mean value 2.62 (SD 1.91) $\mathrm{mmol} / \mathrm{l}, 95 \%$ CI $1.89,3.28, n$ 31). On day 16 plasma phylloquinone concentrations were dose-dependently higher in the supplemented groups, 3-, 5- and 10-fold compared with the non-supplemented group.

MK-4 was detected in ten of thirty-one day 4 samples (mean value $0 \cdot 25$ (SD 0.16) nmol/1, $95 \%$ CI 0.14, 0.37). In the day 16 samples MK-4 was found in fifteen of twentyfive samples including all of the day 16 samples $(n 6)$ of the $4 \mathrm{mg}$ group. The presence of detectable plasma MK-4 in the $4 \mathrm{mg}$ group is different from the other groups $(P=0.051$, Fisher's Exact test $)$. The concentrations, however, did not differ significantly from the other groups (Table 2). No correlation was observed between phylloquinone and MK-4 plasma concentrations.

\section{Vitamin E}

For reason of comparison, the fat soluble vitamin $\mathrm{E}(\alpha-$ plus $\gamma$-tocopherol) in plasma and milk was estimated. Vitamin E levels in breast milk declined significantly $(P<0.001)$ with lactational period: 26.5 (SD 18.5) (n 31), 13.4 (SD 12.5) (n 29), 7.8 (SD 5.7) (n 28), and 7.5 (SD 5.7) (n 28) $\mu \mathrm{mol} / 1$ in the days 4, 8, 16 and 19 samples respectively. Plasma levels of vitamin E on day $16(27 \cdot 0$ (SD 6.1) $\mu \mathrm{mol} / 1, n$ 25) were slightly but significantly lower compared with day 4 (30.4 (SD 6.1) $\mu \mathrm{mol} / 1, n 31, P<0 \cdot 05)$. There were no differences in vitamin $E$ levels between the groups (results not shown). On day 4 plasma vitamin $\mathrm{E}$ correlated with plasma phylloquinone $(r 0.378, P<0.05)$. No correlation was seen between phylloquinone and vitamin $\mathrm{E}$ concentrations in milk.

Plasma triacylglycerol at day 16 was significantly lower compared with day 4 values $(3.25$ (SD 1.17) and 1.86 (SD $1.04) \mathrm{mmol} / \mathrm{l}$ on days 4 and 16 respectively, $P<0.05)$.

\section{Milk-plasma distribution}

No correlation was found between plasma and milk levels of either vitamin $\mathrm{K}$ or vitamin $\mathrm{E}$ (as concentration or as concentration:triacylglycerol ratio). Yet, milk:plasma concentration ratios were found to cluster differently for the three vitamins, with vitamin $\mathrm{E}$ the lowest and MK-4 the highest ratio (Table 3 ).

\section{Discussion}

The primary objective of the present study was to find out if dietary phylloquinone could be a source of tissue MK-4 in man. MK-4 in human tissues has been found to reach, in organs such as brain and kidney, values several-fold higher than phylloquinone (Thijssen \& Drittij-Reijnders, 1996). 
Table 3. Effect of maternal phylloquinone supplementation on the milk:plasma ratios of phylloquinone, menaquinone-4 and vitamin $\mathrm{E}^{*}$

(Mean values, standard deviations, medians and ranges)

\begin{tabular}{|c|c|c|c|c|}
\hline & \multicolumn{2}{|c|}{ Day 4} & \multicolumn{2}{|c|}{ Day 16} \\
\hline & Mean & SD & Mean & SD \\
\hline \multicolumn{5}{|l|}{ Phylloquinone } \\
\hline Mean value & 3.97 & $3 \cdot 11$ & $3 \cdot 66$ & $2 \cdot 16$ \\
\hline Median value & 3.27 & & 3.80 & \\
\hline Range & $0.45-10.73$ & & $0.67-8.24$ & \\
\hline$n$ & 31 & & 25 & \\
\hline \multicolumn{5}{|l|}{ Menaquinone-4 } \\
\hline Mean value & 14.83 & $8 \cdot 3$ & $28 \cdot 1$ & $22 \cdot 4$ \\
\hline Median value & 13.9 & & $25 \cdot 8$ & \\
\hline Range & $2 \cdot 90-28 \cdot 1$ & & $3 \cdot 3-76 \cdot 0$ & \\
\hline$n$ & 10 & & 15 & \\
\hline \multicolumn{5}{|l|}{ Vitamin E } \\
\hline Mean value & 0.97 & 0.62 & 0.33 & 0.24 \\
\hline Median value & 0.92 & & 0.28 & \\
\hline Range & $0 \cdot 13-2 \cdot 27$ & & $0.04-1.00$ & \\
\hline$n$ & 31 & & 25 & \\
\hline
\end{tabular}

${ }^{*}$ For details of subjects and procedures, see p. 220.

The present study showed that all the breast-milk samples analysed contained MK-4. In colostrum the amount was $30-40 \%$ of the phylloquinone concentrations. The presence of MK-4 in human milk has been reported before. Hiraike et al. (1988) found breast milk of Japanese mothers $(n 6)$ to contain $5.1 \mathrm{nmol} \mathrm{MK}-4 / 1$, which was onefourth the level of phylloquinone. MK-7, a product in fermented soyabeans, was discussed as a possible source of breast-milk MK-4. Our results, however, strongly suggest that breast-milk MK4 is derived from dietary phylloquinone: (1) phylloquinone and MK-4 concentrations in breast milk were highly correlated; (2) MK-4 levels in milk increased with phylloquinone supplementation. The results do not give a clue on the site of the phylloquinone - MK-4 conversion in the mothers. The high milk:plasma MK-4 concentration ratios may point to conversion in mammary tissue. Efficient uptake of circulating MK-4 by the mammary gland, however, can not be ruled out. We showed previously that, in rats, dietary phylloquinone and MK-4 distribute mainly to liver and heart. MK-4 in other extra-hepatic tissues, however, is mainly present by local synthesis (Thijssen et al. 1996). The pathway of the conversion is not yet clarified. The gut flora seems not to be involved (Davidson et al. 1998; Ronden et al. 1998). The biological importance of the phylloquinone - MK-4 conversion is still unclear. MK-4 is not the better cofactor in the $\gamma$-carboxylation reaction of in vitro liver systems (Buitenhuis et al. 1990). However, the fact that many tissues synthesize and accumulate MK-4 is suggestive of a physiological function. Thus, MK-4 in breast milk may be of special benefit for the newborn infant. Interestingly, the compound has been found in milk of various species (Indyk \& Woollard, 1997). We found MK-4 in rat milk increased with phylloquinone supplementation to the dam (HHW Thijssen and M-J Drittij, unpublished results).

It has been shown by others that the phylloquinone content of breast milk can be raised by oral phylloquinone supplements (Greer et al. 1997; Bolisetty et al. 1998). The levels that were achieved after $12 \mathrm{~d}$ supplementation were directly related to the supplementation dose. The values for the 2 and $4 \mathrm{mg}$ group are in accordance with those reported by Greer et al. (1997) for 2.5 and $5.0 \mathrm{mg}$ supplements. Thus, to obtain phylloquinone levels in breast milk comparable with levels in infant formulas $(50-60 \mu \mathrm{g} / \mathrm{l}$ is equivalent to $100-130 \mathrm{nmol} / \mathrm{l}$ ) daily oral supplements of $2-4 \mathrm{mg}$ are required. An unknown factor is the bioavailability of phylloquinone in breast milk. It may well be that vitamin K 'physiologically packed' in the fat globules of breast milk has a higher bioavailability. Clearly, mammary tissue does not form a store of fat-soluble vitamins and the breast milk content of phylloquinone rapidly declined after ending the supply.

Contrary to Von Kries et al. (1987), we did not see reduced phylloquinone levels with duration of lactation. Fournier et al. (1987) also reported constant phylloquinone levels for colostrum and mature milk. Relative to the triacylglycerol content, however, phylloquinone was lower in transitional (day 12) and mature (days 16 and 19) milk. In agreement with physiological changes encountered after childbirth (Harzer et al. 1983; King, 2000) triacylglycerol in milk (plasma) raised (declined) during lactational period. As reported by others (Chappell et al. 1985; Boersma et al. 1991) vitamin E levels in transitional and mature milk were found to be $50-70 \%$ lower compared with day 4 levels. Infant milk intake at day 8 post-partum ranges from 400 to $900 \mathrm{~g}$ (Neville et al. 1988) implying that $2-6 \mathrm{mg}$ vitamin $\mathrm{E}$ is eliminated. The daily vitamin $\mathrm{E}$ intake of young adult women in the Netherlands is approximately $11 \mathrm{mg} / \mathrm{d}$ (The Netherlands Nutrition Centre, 1998) explaining the decline of vitamin $\mathrm{E}$ in plasma and milk of lactating mothers. Comparably, the elimination of phylloquinone via lactation would be $0 \cdot 8-2 \cdot 0 \mu \mathrm{g} / \mathrm{d}$. The daily phylloquinone intake of young adult women is not known exactly, but the intake by elderly women in the Dutch population has been reported to be $150-250 \mu \mathrm{g} / \mathrm{d}$ (Jie et al. 1995). 
The remarkable difference between phylloquinone and vitamin $\mathrm{E}$ in milk:plasma concentration ratios can be explained by their difference in transport in the blood. Phylloquinone is mainly transported in the chylomicron and chylomicron-derived triacylglycerol-rich VLDL fraction (Hagstrom et al. 1995; Kohlmeier et al. 1996). Both particles are believed to be the main transporters for lipids to the mammary gland (Hachey et al. 1987). Vitamin E is principally transported by LDL and HDL (Meydani, 1995).

In conclusion, the present study shows that MK-4 in breast milk is derived from dietary phylloquinone. MK-4 is either synthesized locally or selectively secreted. Its presence may indicate a beneficial role of MK-4 for the postnatal development. Phylloquinone supplementation to lactating mothers therefore might serve two goals: (1) to increase vitamin $\mathrm{K}$ levels in breast milk as prophylactic preventer of vitamin $\mathrm{K}$ deficiency bleeding of the newborn infant; (2) to increase MK-4 levels in breast milk.

\section{References}

Billeter M \& Martius C (1960) Über die Umwandlung von Phylloquinon (Vitamin K1) in Vitamin K2(20) im Tierkörper (About the conversion of phylloquinone (vitamin K1) in to vitamin K2(20) in animal tissue). Biochemisches Zeitschrift 333, 430-439.

Boersma ER, Offringa PJ, Muskiet FAJ, Chase WM \& Simmons IJ (1991) Vitamin E, lipid fractions, and fatty acid composition of colostrum, transitional milk, and mature milk: an international comparative study. American Journal of Clinical Nutrition 53, 1197-1204.

Booth SL \& Suttie JW (1998) Dietary intake and adequacy of vitamin K. Journal of Nutrition 128, 785-788.

Bosiletty S, Gupta JM, Graham GG, Salonikas C \& Naidoo D (1998) Vitamin $\mathrm{K}$ in preterm breastmilk with maternal supplementation. Acta Paediatrica 87, 960-962.

Buitenhuis HC, Soute BAM \& Vermeer C (1990) Comparison of the vitamins $\mathrm{K} 1, \mathrm{~K} 2$, and $\mathrm{K} 3$ as cofactors for the hepatic vitamin K-dependent carboxylase. Biochimica et Biophysica Acta 1034, 170-175.

Chappell JE, Francis T \& Clandinin MT (1985) Vitamin A and E content of human milk at early stages of lactation. Early Human Development 11, 157-167.

Conly JM \& Stein K (1992) The production of menaquinones (vitamin K2) by intestinal bacteria and their role in maintaining coagulation homeostasis. Progress in Food and Nutrition Science 16, 307-343.

Cornelissen EAM, von Kries R, Loughnan P \& Schubiger G (1997) Prevention of vitamin K deficiency bleeding: efficacy of different multiple oral dose schedules of vitamin K. European Journal of Pediatry 156, 126-130.

Davidson RT, Foley AL, Engelke JA \& Suttie JW (1998) Conversion of dietary phylloquinone to tissue menaquinone- 4 in rats is not dependent on gut bacteria. Journal of Nutrition 128, 220-223.

Dialameh GH, Taggart WV, Matshiner JT \& Olson RE (1971) Isolation and characterization of menaquinone-4 as a product of menadione metabolism in chicks and rats. International Journal of Vitamin and Nutrition Research 41, 391-400.

Fournier B, Sann L, Guillaumont M \& Leclercq M (1987) Variations of phylloquinone concentration in human milk at various stages of lactation and in cow's milk at various seasons. American Journal of Clinical Nutrition 45, 551-558.

Greer FR (1995) Vitamin K deficiency and hemorrhage in infancy. Clinical Perinatology 22, 759-777.
Greer FR, Marshall SP, Foley AL \& Suttie JW (1997) Improving the vitamin $\mathrm{K}$ status of breastfeeding infants with maternal vitamin K supplements. Pediatry 99, 88-92.

Hachey DL, Thomas MR, Emken EA, Garza C, Brown-Booth L, Adlof RO \& Klein PD (1987) Human lactation: maternal transfer of dietary triglycerides labeled with stable isotopes. Journal of Lipid Research 28, 1185-1192.

Hagstrom JN, Bovill EG, Soll RF, Davidson KW \& Sadowski JA (1995) The pharmacokinetics and lipoprotein fraction distribution of intramuscular vs oral vitamin K1 supplementation in women of childbearing age: effects on hemostasis. Thrombosis and Haemostasis 74, 1486-1490.

Haroon Y, Bacon DS \& Sadowski JA (1986) Liquid-chromatographic determination of vitamin $\mathrm{K} 1$ in plasma, with fluorometric detection. Clinical Chemistry 32, 1925-1929.

Harzer G, Haug M, Dieterich I \& Gentner PR (1983) Changing patterns of human milk lipids in the course of lactation and during the day. American Journal of Clinical Nutrition 37, $612-621$.

Hiraike H, Kimura M \& Itokawa Y (1988) Distribution of K vitamins (phylloquinone and menaquinones) in human placenta and maternal and umbilical cord plasma. American Journal of Obstetrics and Gynecology 158, 564-569.

Indyk HE \& Woollard DC (1997) Vitamin K in milk and infant formulas: determination and distribution of phylloquinone and menaquinone-4. Analyst 122, 465-469.

Jie K-SG, Bots ML, Vermeer C, Witteman JCM \& Grobbee DE (1995) Vitamin K intake and osteocalcin levels in women with and without aortic atherosclerosis: a population-based study. Atherosclerosis 116, 117-123.

Kindberg C, Suttie JW, Uchida K, Hirauchi K \& Nakao H (1987) Menaquinone production and utilization in germ-free rats after inoculation with specific organisms. Journal of Nutrition 117, $1032-1035$.

King JC (2000) Physiology of pregnancy and nutrient metabolism. American Journal of Clinical Nutrition 71S, 218S-225S.

Kohlmeier M, Salomon A, Saupe J \& Shearer M (1996) Transport of vitamin $\mathrm{K}$ to bone in humans. Journal of Nutrition 126, $1192 \mathrm{~S}-1196 \mathrm{~S}$.

Meydan M (1995) Vitamin E. Lancet 345, 170-175.

Neville MC, Keller R, Seacat J, Lutes V, Neifert M, Casey C, Allen J \& Archer P (1988) Studies in human lactation: milk volumes in lactating women during the onset of lactation and full lactation. American Journal of Clinical Nutrition 48, $1375-1386$.

Ronden JE (1998) Absorption, tissue distribution and bioactivity of vitamin $\mathrm{K}$ and related compounds in the rat. $\mathrm{PhD}$ Thesis, University of Maastricht.

Ronden JE, Drittij-Reijnders MJ, Vermeer C \& Thijssen HHW (1998) Intestinal flora is not an intermediate in the phylloquinone-menaquinone-4 conversion in the rat. Biochimica et Biophysica Acta 1379, 69-75.

Ramotar K, Conly JM, Chubb H \& Louie TJ (1984) Production of menaquinones by intestinal anaerobes. Journal of Infectious Disease 150, 213-218.

Shearer MJ (1992) Vitamin K metabolism and nutriture. Blood Reviews 6, 92-104.

Sutor AH, Von Kries R, Cornelissen EAM \& McNinh AW (1999) Vitamin K deficiency bleeding (VKDB) in infancy. Thrombosis and Haemostasis 81, 456-461.

Suttie JW (1995) The importance of menaquinones in human nutrition. Annual Reviews of Nutrition 15, 399-417.

The Netherlands Nutrition Centre (1998) Dutch Food Intake in 1997-1998. Den Haag: Voedingscentrum.

Thijssen HHW \& Drittij-Reijnders MJ (1994) Vitamin K distribution in rat tissue: dietary phylloquinone is a source of 
tissue menaquinone-4. British Journal of Nutrition 72, 415425.

Thijssen HHW \& Drittij-Reijnders MJ (1996) Vitamin K status in human tissues: tissue-specific accumulation of phylloquinone and menaquinone-4. British Journal of Nutrition 75, 121-127.

Thijssen HHW, Drittij-Reijnders MJ \& Fischer MAJG (1996) Phylloquinone and menaquinone-4 distribution in rats: synthesis rather than uptake determines menaquinone-4 organ concentrations. Journal of Nutrition 126, 537-543.

Trumbo P, Yates AA, Schlicker S \& Poos M (2001) Dietary reference intakes: Vitamin A, vitamin $\mathrm{K}$, arsenic, boron, copper, iodine, iron, manganese, molybdenum, nickel, silicon, vanadium and zinc. Journal of the American Dietetic Association 101, 294-301.

Will BH, Usui Y \& Suttie JW (1992) Comparative metabolism and requirement of vitamin $\mathrm{K}$ in chicks and rats. Journal of Nutrition 122, 2354-2360.

Von Kries R, Shearer M, McCarthy PT, Haug M, Harzer G \& Gobel U (1987) Vitamin K1 content of maternal milk: influence of the stage of lactation, lipid composition, and vitamin K1 supplements given to the mother. Pediatric Research 22, 513-517. 